\title{
A raiva de Pasolini - UMA TRADUÇÃO COMENTADA
}

Aline Buaes

N sua coluna semanal na revista Vie Nuove, em 20 de setembro de 1962, o escritor publica na íntegra o argumento do filme que estava produzindo naqueles meses, o documentário "A raiva".

Esquecido durante décadas do grande público, devido à escassa distribuição na época, o filme La rabbia (1963), documentário dividido em duas partes e dirigido por Pasolini e Giovannino Guareschi, foi recentemente restaurado pela Cineteca de Bolonha e uma nova versão, dirigida pelo cineasta Giuseppe Bertolucci, "uma hipótese de reconstrução" do filme original, incluindo partes cortadas em 1963, foi apresentada na edição 2008 do Festival de Cinema de Veneza, com o titulo La Rabbia di Pasolini (Itália, 2008).

O projeto do filme La rabbia começou em 1962 quando um pequeno produtor cinematográfico confiou a Pasolini o material de arquivo pertencente a um cinejornal, "Mondo Libero". Além das imagens deste cinejornal, Pasolini também utilizou imagens dos Arquivos Itália-URSS e reproduções de livros de arte e revistas semanais. Como trilha sonora, inseriu um texto em versos, narrado pelo escritor Giorgio Bassani, e um comentário em prosa, narrado por Renato Guttuso.

"Com o filme La rabbia (1963), Pasolini idealizou 'um novo gênero cinematográfico', um poema fílmico baseado em um comentário em prosa e em versos onde a denúncia se alterna com o lamento e a análise política e social, tecendo uma complexa dialética com imagens tiradas de cinejornais, filmagens de arquivo, reproduções de quadros e fotografias", afirma Roberto Chiesi na contracapa do livro La rabbia (PASOLINI, P. P. Org. Roberto Chiesi. Bologna: Cineteca di Bologna, 2008), edição lançada recentemente pela Cineteca de Bolonha com o texto original de Pasolini ao lado de algumas das imagens mais significativas utilizadas na montagem original.

$\mathrm{Na}$ apresentação do livro La Rabbia, Chiesi também afirma que este texto de Pasolini mostra "o momento de uma passagem crucial, porque a Itália está queimando rapidamente as etapas de transformação de país agrícola para um país industrializado, com uma violenta e irreversível transformação social e cultural da qual Pasolini será a testemunha mais perspicaz e sofrida" (Pasolini, op. cit., p. 7).

"Quando escreve La rabbia, Pasolini acredita ainda na utopia da revolução dos humildes, acredita ainda na União Soviética de Krusciov. As palavras de Pasolini 
exaltam as lutas da Argélia e de Cuba, (...), relembram a tragédia das repressões soviéticas na Hungria (...), celebram as missões espaciais dos cosmonautas soviéticos (...), descrevem a tragédia de uma vítima da sociedade do espetáculo, Marilyn Monroe, e evocam, com um tom visionário, a angústia de viver sobre a sombra do pesadelo nuclear", continua Chiesi. (Pasolini, op. cit., p. 8)

\section{A raiva ${ }^{1}$}

O que aconteceu no mundo depois da guerra e do pós-guerra?

A normalidade.

Já, a normalidade. No estado de normalidade não se olha ao redor, tudo ao redor se apresenta como "normal", sem a excitação e emoção dos anos de emergência. O homem tende a se adormecer na própria normalidade, se esquece de refletir, perde o hábito de se julgar, não sabe mais se perguntar quem é.

É então que se cria artificialmente o estado de emergência. E quem o faz são os poetas. Os poetas, estes eternos indignados, estes modelos da raiva intelectual e da fúria filosófica.

Houve acontecimentos que marcaram o fim do pós-guerra, suponhamos, na Itália, a morte de De Gasperi. ${ }^{2}$

A raiva começa ali, naquele grande e melancólico funeral.

O estadista antifascista e reconstrutor está "morto": a Itália se conforma no luto da morte e se prepara, justamente, para reencontrar a normalidade dos tempos de paz, da paz verdadeira e esquecida.

Alguém, o poeta, ao contrário, se recusa a esta acomodação.

Ele observa, com indiferença - a indiferença do desgosto e da raiva - os episódios extremos do pós-guerra: o retorno dos últimos prisioneiros, recordem, em trens miseráveis, o retorno das cinzas dos mortos ${ }^{3} \ldots$ E...

...o ministro Pella ${ }^{4}$ que, arrogantemente, ratifica o desejo da Itália em participar da Europa Unida.

É assim que recomeça, na paz, o mecanismo das relações internacionais. Os ministérios se sucedem aos ministérios, os aeroportos são um contínuo ir e vir de ministros, embaixadores, diplomatas, que descem pela escada do avião, sorriem, dizem palavras vazias, estúpidas, superficiais, falsas.

${ }^{1}$ Publicado com o título "Gli anni della rabbia" no número 38, do ano de 1962, da revista Vie Nuove. In: Le belle bandiere: Dialoghi 1960-1965. Roma, Riuniti, 1996, II ed., p. 222.

${ }^{2}$ Alcide De Gasperi (1881-1954), fundador e grande líder da Democracia Cristã, foi primeiro-ministro italiano por oito mandatos consecutivos (1945-1953). Em maio de 1954 foi eleito presidente da Comunidade Europeia do Carvão e do Aço (Ceca). Seus funerais foram celebrados solenemente no dia 21 de agosto de 1954. (Pasolini, op. cit., 2008, p. 212)

${ }^{3}$ As urnas com as cinzas dos cerca de oito mil soldados italianos mortos no ataque do exército alemão contra a ilha grega de Cefalônia, logo após armistício de 1943, retornaram à Itália apenas em 1953. (Pasolini, op. cit., p. 212)

${ }^{4}$ Giuseppe Pella (1902-1981), deputado democrata-cristão desde 1946, diversas vezes ministro da Economia, no biênio 1953-1954 foi primeiro-ministro e ministro das Relações Exteriores da Itália. (Idem, p. 212) 
O nosso mundo, em paz, fervilha com um ódio ameaçador, o anticomunismo. E, sobre o fundo cinzento e deprimente da Guerra Fria e da Alemanha dividida, aparecem as novas figuras dos protagonistas da nova história.

Krusciov, Kennedy, Nehru, Tito, Nasser, De Gaulle, Fidel Castro, Ben Bella.

Até que se chega a Genebra, ao encontro dos quatro Grandes. ${ }^{5}$ E a paz, ainda abalada, ruma para uma ordenação definitiva. E a raiva do poeta contra esta normalização, que é consagração da potência e do conformismo, não pode se não crescer ainda mais.

O que é que deixa o poeta insatisfeito?

Uma infinidade de problemas que existem e ninguém é capaz de resolver. E, sem a sua resolução, a paz, a verdadeira paz, a paz do poeta, é irrealizável.

Por exemplo, o colonialismo. Esta violência retrógrada de uma nação sobre outra, com seu rastro de mártires e mortos.

Ou a fome, para milhões e milhões de subproletários.

Ou o racismo. O racismo como câncer moral do homem moderno e que, assim como o câncer, tem infinitas formas. É o ódio que nasce do conformismo, do culto da instituição, da prepotência da maioria. É o ódio por tudo o que é diferente, por tudo o que não se encaixa na norma e que, portanto, abala a ordem burguesa. Infeliz de quem é diferente! Este é o grito, a fórmula, o slogan do mundo moderno. Portanto, ódio contra os negros, os pardos, os homens de cor. Ódio contra os judeus, ódio contra os filhos rebeldes, ódio contra os poetas.

Linchamentos em Little Rock, linchamentos em Londres, linchamentos no Norte da África, insultos fascistas aos judeus.

É assim que explode novamente a crise, a eterna crise latente.

Os fatos da Hungria, ${ }^{6}$ de Suez. ${ }^{7}$

A Argélia que começa aos poucos a se encher de mortos. ${ }^{8}$

${ }^{5} \mathrm{O}$ encontro dos "quatro grandes" (Estados Unidos, Grã-Bretanha, França e União Soviética) ocorreu em Genebra em julho de 1955, quando foram discutidos os temas do desarmamento e das relações Ocidente-Oriente. (Ibidem, p. 212)

${ }^{6}$ Em outubro de 1956 os estudantes húngaros organizaram uma manifestação de solidariedade com a Polônia que se transformou em uma insurreição contra o governo e o exército soviético estabelecido na Hungria. Imre Nagy, comunista reformador, eleito chefe do governo húngaro após a morte de Stálin (1953), anunciou a formação de um novo governo no final de outubro e conseguiu a retirada das tropas soviéticas do país. Mas, quando Nagy anunciou, no início de novembro, a saída da Hungria do Pacto de Varsóvia, o secretário do Partido Comunista húngaro, Janos Kadar, pediu a intervenção da União Soviética, que, alguns dias depois, ocupou militarmente Budapeste, reprimindo violentamente os apoiadores de Nagy, que foi processado e condenado à morte em 1958. Kadar foi então nomeado primeiro-ministro. (Pasolini, op. cit., 2008, p. 213)

${ }^{7}$ Em julho de 1956, Nasser, presidente do Egito, decretou a nacionalização do Canal de Suez. Em outubro, Israel iniciou uma ação militar contra o Egito, com o apoio sucessivo de França e Inglaterra. O exército de Nasser foi derrotado, mas os Estados Unidos e a União Soviética pressionaram os países europeus para que se retirassem do conflito. Em novembro, a ONU conseguiu suspender as ações militares e instituiu uma força internacional para garantir a paz na região. (Idem, p. 213)

${ }^{8}$ A guerra da independência da Argélia começou em 1954, quando foi constituído o Comitê Revolucionário Clandestino (posteriormente denominado FLN - Frente de Libertação Nacional). A guerra provocou várias crises de governo na França até que, em dezembro de 1958, Charles De 
O mundo parece, por algumas semanas, aquele de alguns anos atrás. Canhões que disparam, escombros, cadáveres pelas ruas, filas de refugiados esfarrapados, as paisagens cobertas de neve.

Mortos estripados sob o sol forte do deserto.

A crise, mais uma vez, se resolve no mundo. Os novos mortos são lamentados e homenageados. E recomeça, cada vez mais integral e profunda, a ilusão da paz e da normalidade.

Mas, junto à velha Europa, que se reorganiza nos seus princípios solenes, nasce a Europa moderna:

o Neocapitalismo;

o MCE, os Estados unidos da Europa, ${ }^{9}$ os industriais esclarecidos e "fraternos", os problemas das relações humanas, do tempo livre, da alienação.

A cultura ocupa novos espaços, um novo fôlego de energia criativa nas letras, no cinema, na pintura. Um enorme serviço aos grandes detentores do capital.

O poeta servil se anula, anulando os problemas e reduzindo tudo a forma.

O mundo potente do capital tem, como audaciosa bandeira, um quadro abstrato.

Assim, enquanto por um lado a cultura de alto nível fica cada vez mais refinada e para poucos, estes "poucos" se tornam, ficticiamente, muitos: se tornam a "massa". É a vitória do "digest" e das "revistas ilustradas", mas principalmente da televisão. O mundo distorcido por estes meios de difusão, de cultura, de propaganda, se torna cada vez mais irreal: a produção em série, incluindo das ideias, o torna monstruoso.

O mundo das revistas, do lançamento mundial de produtos humanos, é um mundo que mata.

Pobre e doce, Marilyn, irmãzinha obediente, carrega a tua beleza como uma fatalidade que alegra e mata. ${ }^{10}$

Talvez você tenha tomado o caminho certo, nos ensinou. O teu branco, o teu ouro, o teu sorriso sensual por gentileza, passivo por timidez, por respeito aos grandes que te queriam assim, você, que permaneceu menina, são coisas que nos levam a aplacar a raiva no choro, a virar de costas para esta realidade condenada, à fatalidade do mal.

Porque, enquanto o homem explorar o homem, enquanto a humanidade for dividida em patrões e servos, não existirá nem normalidade nem paz. A razão de todo o mal do nosso tempo está aqui.

E ainda hoje, nos anos 60, as coisas não mudaram, a situação dos homens e da sua sociedade é a mesma que produziu as tragédias de ontem.

Gaulle foi eleito presidente e encarregou o comandante Jacques Massu como chefe das forças de repressão. E 1958, o FLN formou um governo provisório da república argelina. A Argélia conquistou a independência apenas em julho de 1962. Em oito anos, cerca de um milhão de pessoas morreram. (Ibidem, p. 214)

9 O acordo para o Mercado Comum Europeu (MCE) entrou em vigor em janeiro de 1958 e foi o precursor da atual União Europeia.

${ }^{10}$ Marilyn Monroe morreu em Hollywood no dia 4 de agosto de 1962. 
Veem estes? Homens severos, de terno, elegantes, que sobem e descem dos aviões, que correm em automóveis potentes, que se sentam em escrivaninhas grandiosas como tronos, que se reúnem em anfiteatros solenes, em sedes esplêndidas e severas. Estes homens, com cara de cães ou de santos, de hienas ou de águias, estes são os patrões.

E veem estes? Homens humildes, vestidos em trapos ou em roupas feitas em série, míseras, que vão e vêm por ruas abarrotadas e imundas, que passam horas e mais horas em um trabalho sem esperança, que se reúnem humildemente em estádios ou tabernas, em casebres miseráveis ou em trágicos arranha-céus. Estes homens, com caras iguais às dos mortos, sem feições e sem luz se não aquela da vida, estes são os servos.

É desta divisão que nasce a tragédia e a morte.

A bomba atômica com a sua tampa fúnebre que se estende por céus apocalípticos é o fruto desta divisão.

Parece não existir solução para este impasse, no qual o mundo da paz e do bem-estar se agita. Talvez apenas uma reviravolta imprevista, inimaginável... uma solução que nenhum profeta pode intuir... uma daquelas surpresas que a vida tem quando quer continuar... talvez...

Talvez o sorriso dos astronautas. ${ }^{11}$ Aquele, talvez, seja o sorriso da esperança e da paz verdadeira. Com os caminhos da terra interrompidos, fechados ou ensanguentados, eis que se abre, timidamente, o caminho do cosmo.

(Vie Nuove, 20 de setembro de 1962)

\section{Poesia em forma de polêmica - Pier Paolo Pasolini}

Poesia publicada originalmente pelo escritor italiano Pier Paolo Pasolini em sua coluna na revista semanal Vie Nuove, em 14 de janeiro de 1965.

Este poema contém referências explícitas a experiências vividas por Pasolini pouco antes de publicar o texto. Em dezembro de 1964, Pasolini passou alguns dias em Paris participando de eventos para promover o lançamento na França do seu filme O Evangelho segundo São Mateus. O mais polêmico destes eventos foi um debate ocorrido na catedral de Notre Dame, que pela primeira vez na sua história recebia um evento do gênero, promovido por uma organização católica e do qual participaram, além de cerca de cinco mil estudantes universitários, também altos expoentes da Igreja local. O evento se encerrou com uma missa cantada. Alguns dias mais tarde, Pasolini se encontrou com o filósofo e escritor francês Jean-Paul Sartre em um café de Paris, o café de Pont-Royal. De Paris, Pasolini seguiu em viagem por outras capitais europeias para apresentar seu filme, incluindo Budapeste, onde o filme teve uma ótima recepção.

${ }^{11} \mathrm{O}$ primeiro homem a atingir o espaço foi o russo Iuri Gagarin, lançado em 12 de abril de 1961, a bordo da espaçonave Vostok I. 


\section{Poesia em forma de polêmica ${ }^{12}$}

Você, Sartre, não considera ruim

que Notre Dame tenha sido iluminada pelos seus padres

para este ambíguo interlocutor?

Não!

O Peperizzo de Pressis Passe vai embora.

No Café de Port Royal, cai a escuridão das duas.

Não!

É necessário que os escândalos aconteçam, mas eu não me escandalizo

E coitado do homem para quem os escândalos acontecem. Mas eu não me escandalizo por nada! E então? Cristo some no Café de Port Royal (Existe

alguém neste mundo que, não se escandalizando, apaga alguns parágrafos do Evangelho).

Mas lá (no Leste) eles se escandalizam.

$\mathrm{E}$, além do mais (acrescenta o doce homem que não se escandaliza sentado na poltrona como uma esplêndida cigarra mensageira do amor) não existe a "crítica ao marxismo".

Tudo, portanto, se explica.

Mas enquanto isso uma outra cigarra

sozinha em dois quartinhos em Budapeste, sobre o Danúbio, onde se chega

por uma estrada de metal preto como um corredor

entre baixos nevoeiros,

através de uma entrada sem porteiro,

com seis grandes monumentos que contêm a morte da pequena-burguesia

que lá viveu e agora deixa a dor de uma morte não lastimada

- seis monumentos, deteriorantes sobre seis degraus, cheios

da forma da dor agora tomada pela grandeza do povo,

lixos gélidos pela pressão de nevoeiros externos implacáveis

- seis monumentos destapados, com parte do seu conteúdo

ardentes cascas de um fruto mediterrâneo pateticamente expatriado...

Basta.

No quinto andar vem a cigarra para abrir a porta,

12 Publicado com o título "Poesia in forma di polemica" no número 2, do ano de 1964, da revista Vie Nuove. In: Le belle bandiere: Dialoghi 1960-1965. Roma, Riuniti, 1977, p. 287. 
não se escandaliza, mas não se apaixona, as máquinas para pensar não funcionam. Não há ânsia por aquilo que contesto.

A cigarra tem ainda "muito por cantar", não tem tempo para responder. Le vieux! (O abraçarei indo embora, terei coragem de lhe dizer "Por toda a década de Cinquenta você foi nossa Esfinge, deixa eu abraçar você"?)

\section{Era}

esta cigarra prisioneira de um Quinto andar e da Filosofia.

A sua luz era carismática.

Podem existir duas partes de um pensamento, mas não duas partes de luz.

Rejuvenescido pela idade das cigarras, pareço

uma formiga aprendiz, e a minha alma realmente,

assim como a de um garoto

precisa voltar para a pátria com algum presente.

Apalpo no bolso do paletó italiano

as duas batidas parisienses, confiante da vitória.

Não posso abraçar a pobre cigarra húngara

que os seus compatriotas desprezam (amusez-vous, avec le vieux):

homens escuros, funcionários, jovens literatos

que de Budapeste são a nova alma, como um novo Natal, não sabem nem mesmo dizer onde moram, eu sou talvez um dos poucos que têm notícia, como um jovem jornalista,

e quando às sete da noite

faz noite alta (aquela silenciosa que antecede as alvoradas)

sobre a capital das esfinges e da dor exposta como uma bandeira, vou embora sem presentes

com os cumprimentos para Cesare Cases e Elsa Morante.

Vou embora, cumprido o meu dever de jornalista desconhecido com sua face ameaçadora e as suas cruéis pretensões de jovem, vou embora

como quando se deixa para sempre uma cidade que não se viu.

Adeus, Lukács, pombinha entre as esfinges, quanto ainda a pomba deve cantar com seu cérebro de homem, entre as esfinges depositárias do silêncio! 


\section{Um marxista em Nova York ${ }^{13}$}

Entrevista de Oriana Fallaci com Pier Paolo Pasolini publicada originalmente na revista L'Europeo de 13 de outubro de 1966.

Eis que ele chega: pequeno, frágil, consumido pelos seus milhares de desejos, pelas milhares de angústias e tristezas, e vestido como um garoto de college. Como aqueles sujeitos esbeltos, esportivos, que jogam baseball e fazem amor dentro de carros. Pulôver caramelo, com bolso de couro na altura do peito, calças de veludo caramelo, um pouco justas, sapatos de camurça com sola de borracha. Realmente, não aparenta os quarenta e três anos que tem. Para descobrir, estes quarenta e três anos, é preciso que vá até a janela, onde a luz bate cruel sobre seu rosto e atinge aqueles olhos brilhantes, doloridos, aquela face magra, envelhecida, a pele esticada nas maçãs do rosto revelando seu crânio. Pelo cansaço, suponho. À noite, escapa dos convites e vai sozinho pelas ruas mais obscuras do Harlem, de Greenwich Village, do Brooklyn, ou no porto, nos bares onde nem a polícia entra, procurando a América suja, infeliz e violenta que se dedica aos seus problemas e ao seu gosto, e volta ao amanhecer para o hotel em Manhattan, com as pálpebras inchadas, o corpo dolorido pela surpresa de estar vivo. Todos pensamos que, se não parar, o encontraremos com uma bala no coração ou com a garganta cortada. Mas é louco de circular assim por Nova York? Está em Nova York há dez dias. Veio para o Festival de Cinema, que selecionou dois filmes seus. Estou realmente curiosa para saber se a América agrada a este marxista convicto, a este cristão enraivecido, enfim, a Pasolini.

Dez dias é pouco para dar uma opinião, é verdade, mas Orson Welles uma vez me disse que para compreender um país é preciso dez dias ou dez anos: no décimo primeiro dia você se habitua e não enxerga mais nada. No décimo primeiro dia, amanhã, ele vai embora. Por isso, insisti para que viesse me encontrar para tomar um drink. "Whisky?", lhe pergunto. "Cerveja? Conhaque?". "Coca-cola" responde. A janela se abre para uma rua cheia de arranha-céus, um ao lado do outro, um depois do outro, do East River ao Hudson. Olhá-los dá vertigem, faz a gente se sentir em uma armadilha, como um animal que tem sede de verde. Ou de silêncio. Pelo vidro entreaberto, entra o inferno: o rosnar dos motores, o som das buzinas, o martelar das escavadeiras, as sirenes. A cidade ligou as calefações e o pó negro se gruda até mesmo nos cílios, deixando nos cegos. Chove, é um daqueles dias que tudo irrita, desanima. Mas ele bebe com gosto a sua Coca-cola e exclama de uma só vez:

"Gostaria de ter dezoito anos para viver uma vida inteira aqui."

${ }^{13}$ In: PASOLINI, P. P. Saggi sulla politica e sulla società. Org. W. Siti e S. De Laude, 1 vol. 4 ed. Milano: Mondadori, 2006, pp. 1597-1606. 


\section{Aqui?! Em Nova York?}

"É uma cidade mágica, fascinante, belíssima. Uma daquelas cidades fortunadas que receberam a dádiva. Como alguns poetas, que toda vez que escrevem um verso, fazem uma poesia linda. Lamento não ter vindo aqui muito antes, vinte ou trinta anos atrás, para ficar. Nunca tinha me acontecido conhecendo um país. Com exceção da África, talvez. Mas na África gostaria de ir e ficar para não me matar. A África é como uma droga que você toma para não se matar, uma fuga. Nova York não é uma fuga, é um empenho, uma guerra. Nos provoca uma vontade de fazer, enfrentar, mudar. Gostamos dela exatamente como gostamos das coisas aos vinte anos. Compreendi isso logo que cheguei. Cheguei de trem vindo de Montreal. Desci em uma enorme estação imersa no escuro, no metrô. Não havia carregadores e minha mala pesava. Mesmo assim, eu andava como se fosse leve. Andava na direção de uma luz ofuscante, ao final de um túnel, e quando saí, a cidade me agrediu como uma aparição. Jerusalém que aparece aos olhos do Crucificado. Não me sentia estrangeiro, aprendi imediatamente a andar pelas ruas como se tivesse nascido aqui, mesmo assim não a reconhecia. Porque ninguém jamais representou Nova York. A literatura não a representou, com exceção das histórias em quadrinhos de Pafúncio e Marocas, ${ }^{14}$ sobre Nova York existem apenas as poesias de Allen Ginsberg. A pintura não a representou. Não existem quadros de Nova York. O cinema não a representou, porque... Não sei. Talvez porque não seja filmável. De longe é como os Montes Dolomiti, muito fotogênica, muito maravilhosa, e incômoda. De perto, de dentro, não se enxerga. A lente não consegue captar o início e o fim de um arranha-céu. Mas não é apenas a beleza física que importa. É a sua juventude. É uma cidade de jovens, a cidade menos crepuscular que já conheci. E como são elegantes os jovens aqui."

\section{Elegantes?!}

"Possuem um gosto fantástico. Olha como se vestem. No modo mais sincero, mais anticonformista possível. Eles não se importam em nada com as regras pequeno burguesas ou populares. Aqueles blusões chamativos, aquelas jaquetas baratas, aquelas cores incríveis. Eles não se vestem, eles se fantasiam. Como quando somos criança e vestimos o roupão dos avós. E assim, fantasiados, eles se vão, orgulhosos, conscientes da sua elegância que não é uma elegância mítica ou ingênua. Dá vontade de imitá-los e talvez os imitemos porque, afinal, onde poderemos nos vestir assim? Em Roma? Em Milão? Em Paris? Lá sempre tenho medo que as pessoas se virem e me olhem. Aqui não tenho nenhum complexo, posso andar vestido como quero, sem que ninguém me incomode com a sua curiosidade. Ontem, na 45th Street, vi um homem que estava morrendo. Tinha nas mãos um pequeno pacote, o qual olhou fixamente e depois atirou com tanta força que o pacote

${ }^{14}$ Considerada a primeira história em quadrinhos de repercussão mundial, de George McManus, narra a história de um casal de imigrantes irlandeses que fica rico em Nova York. 
se quebrou. Quem sabe o que tinha ali dentro. Depois se apoiou na parede, colocou a cabeça entre os braços, escorregou pouco a pouco pelo chão e ficou ali chorando. Ou melhor, morrendo. Sem que ninguém parasse para olhá-lo, muito menos para lhe oferecer um copo de água, uma ajuda. Na noite anterior, perto do Metropolitan, vi um idoso deitado na calçada, coberto por um cobertor. Ao seu lado estava um garoto, bonito e elegante como você diz, com sapatos de couro impecável, meias finas, calças bem cortadas, um pulôver maravilhoso. O idoso apertava a mão do garoto sobre seu peito e o seu rosto estava branco, já retocado pela morte. As pessoas passavam e não paravam, algumas riam. Mas isto é ruim? Ou não seria pior o nosso parar e observar com curiosidade? Não se sabe se o silêncio deles é falta de piedade, talvez seja uma forma superior de piedade. A piedade de não se aproximar, de não olhar com curiosidade...".

A América é realmente uma mulher fatal, seduz a todos. Até agora não conheci um comunista que tenha desembarcado aqui e não tenha perdido a cabeça. Chegam cheios de hostilidades, preconceitos, até desprezo, e imediatamente são tocados pela Revelação, pela Dádiva. Tudo está bom, gostam de tudo, voltam apaixonados, com os olhos cheios de lágrimas. Sim ou não, Pasolini? Ele sacode os ombros, indiferente.

"Eu sou um marxista independente, nunca me inscrevi no partido e sou apaixonado pelos Estados Unidos desde pequeno. Porquê, não sei muito bem. A literatura americana, por exemplo, nunca me agradou. Não gosto de Hemingway, nem de Steinbeck, muito pouco de Faulkner. De Melville pulo para Allen Ginsberg. O establishment americano nunca pôde, obviamente, se conciliar com a minha crença marxista. E então? O cinema, talvez. Durante toda a minha juventude fui fascinado pelos filmes americanos, ou seja, por uma América violenta e cruel. Mas não foi essa a América que encontrei. Esta é uma América jovem, desesperada, idealista. Existe nela um grande pragmatismo e ao mesmo tempo um idealismo enorme. Nunca são cínicos ou céticos, como somos nós. Nunca são indiferentes ou realistas: vivem sempre dentro de um sonho e precisam idealizar tudo. Mesmo os ricos ou aqueles que possuem o poder em suas mãos. O verdadeiro momento revolucionário de todo o mundo não está na China e nem na Rússia, está na América. Me explico. Se você vai a Moscou, a Praga ou a Budapeste percebe que a revolução fracassou. O socialismo colocou no poder uma classe de dirigentes e o operário não é dono do próprio destino. Se você vai à França ou à Itália, percebe que o comunista europeu é um homem vazio. Mas se você vem até a América, descobre a esquerda mais linda que um marxista possa descobrir nos dias de hoje. Conheci os jovens do SNCC, ${ }^{15}$ aqueles estudantes que organizam os negros no sul. Me lembram os primeiros cristãos, existe neles a mesma plenitude com a qual Cristo dizia ao jovem rico: Para vir comigo, deves abandonar

15 Student Non-violent Coordinating Committee. 
tudo, quem ama o pai e a mãe, me odeia. Não são comunistas nem anticomunistas, são místicos da democracia. A revolução deles consiste em levar a democracia às mais extremas e arriscadas consequências. Após conhecê-los, tive uma ideia. Ambientar na América o meu filme sobre São Paulo. Quero transferir toda a ação de Roma para Nova York, situando-a nos tempos atuais mas sem mudar nada, sendo muito fiel às suas cartas. Nova York possui muitas analogias com a antiga Roma, da qual fala São Paulo. A corrupção, as clientelas, o problema dos negros, dos drogados. E a tudo isto São Paulo dava uma resposta santa, ou seja, escandalosa, exatamente como os jovens do SNCC..."

Às 19h Pasolini tem um encontro com Herbert Blau, diretor teatral do Lincoln Center, que o convidou para jantar. Não se encontram táxis a esta hora e assim vamos a pé. Cai uma chuva fina e irritante. Mas ele caminha sem senti-la, talvez admirando-a, e repete que enxerga as casas de Pafúncio e Marocas, no fundo, é como se voltássemos a ser criança. Aquela tristeza inchada com muitas aflições quase desapareceu dos seus olhos.

"O aspecto mais importante desta cidade é a miséria."

Miséria?! Em Nova York?!

"Sim, o mesmo tipo de miséria, ou pobreza, que se encontra nas ex-colônias que se tornaram independentes recentemente. O mesmo tipo de pobreza que se encontra em Calcutá, Bombaim, Casablanca. Não é uma miséria econômica, aquela miséria de quem não tem o que comer. Falo sobre uma miséria psicológica. Aquela imundície difusa, aquela precariedade. As ruas mal asfaltadas que se enchem de poças quando chove. As paredes pretas ou marrons, construídas com pressa para serem destruídas com pressa. A Park Avenue, os esplêndidos arranha-céus de vidro, são como as pirâmides. Estar aqui hoje é como estar no Egito na época que os escravos construíam as pirâmides. Nunca se disse que os escravos no Egito viviam mal. Talvez até fossem alegres, no desespero, e à noite saíam para se divertir e beber... Mas não me refiro a isto. O aspecto mais importante continua sendo esta miséria de ex-colônia, de subproletariado."

Subproletariado? Em Nova York?

"Certamente. Os estigmas da mesma origem subproletária estão em todos. À primeira vista, não se percebe nem mesmo a diferença de classe. Como em Moscou, quando você caminha pensando que todos são iguais. Naturalmente a diferença existe, mas eles não se dão conta e nós também não. E sabe por quê? Porque não existe neles a consciência de classe. A confusão para alguém que vem da Itália é muito pior do que na África ou na Índia. Quero dizer que quando você entra em Calcutá e Cartum, você entra no coração de uma raça, de um contexto social: a classe operária, burguesa, pequeno burguesa, cada uma com a sua consciência de existir. E quando você entra em Nova York, encontra o quê? Um fogo de artifício de raças assemelhadas e que se tornaram parecidas devido ao mesmo sistema, a mesma base: o subproletariado. Olhe para o operário norte-americano, para esta 
mistura monstruosa e fascinante de subproletário e pequena burguesia. Não existe o operário enquanto tal porque não existe nele a consciência da classe operária. Um buraco sem fundo. Mas para qualquer lugar dos Estados Unidos que você olhar, para uma alma, uma rua ou um ambiente, estará diante de um buraco negro. Como se você espiasse de cima de um arranha-céu. Isto é bom ou ruim? Não sei, estou confuso. Na Europa, me pareceria negativo, aqui não. Admiro o momento revolucionário americano, mas certamente o meu coração está com o pobre negro ou o pobre calabrês, e, ao mesmo tempo, respeito o establishment, o sistema americano... Devo voltar aqui e aprofundar."

O restaurante onde encontramos Herbet Blau é famoso pelas lagostas grelhadas. Jantar? Lagostas? Pasolini acorda como um sonâmbulo do labirinto das suas confusões e pede um copo de leite e uma salada de frutas sem laranja. Sofre devido a uma úlcera, deve passar por uma operação em breve, se alimenta como um bebê. Ao falar de teatro, projetos, Blau olha para ele um pouco assombrado: este revolucionário que se alimenta como um bebê. Despedir-se-ão em breve, reciprocamente entediados. Após o jantar, Blau o levou ao Lincoln Center para assistir os ensaios de uma comédia de época. Mas Pasolini não se importa com as comédias de época, com o mecanismo eletrônico que troca o cenário em poucos segundos, gira o palco, ergue a plateia. No seu mundo não tem lugar para este tipo de maravilhas. Assim como não tem lugar para os arranha-céus de vidro, Park Avenue, o lançamento de um foguete, o transplante cirúrgico de um coração vivo. A América bela, limpa e confortável que agrada a quem espera no Paraíso. Como Rimbaud (ou alguns mártires), ele quer sempre voltar ao inferno, aos bairros onde corre o risco de levar um tiro no peito, encontros trágicos e talvez perversos, a punição, o Greenwich Village como descreveu Elsa Morante, o Harlem como viu na noite passada, que foi uma noite maravilhosa. Apresentaram-lhe um sindicalista negro, de extrema esquerda, daqueles que não aceitam o sistema da não violência defendido por Martin Luther King, e estão prontos para matar. O sindicalista o levou até a casa de um operário que caiu do $46^{\circ}$ ao $42^{\circ}$ andar, onde permaneceu milagrosamente pendurado por um fio. O operário era um negro idoso, deitado em uma cama e que ria feliz, feliz, e isto foi tão comovente. Rapidamente se despede de mim, impaciente, um rápido aperto de mão, e se vai, sozinho no escuro.

Hoje ele vai embora e tem muitas coisas para fazer. Em primeiro lugar, posar para um tipo que insistiu muito e parece que se chama Avalon. "Dick Avedon?". "Sim, alguma coisa assim". "Não sabe quem é Dick Avedon?". "Não, quem é?". "Talvez o maior fotógrafo dos Estados Unidos, sem dúvida um dos maiores do mundo." "Ah sim?" Avedon insistiu para que Pasolini fosse até seu estúdio perto das $11 \mathrm{~h}$, mas atrasou-se porque um mendigo bêbado dormia nas escadas, e um mendigo bêbado dormindo vale cem fotografias de Avedon.

Escutava ele com paciência materna e doçura. Antes de deixá-lo, lhe deu alguns dólares e certamente agora olha com menos interesse para a enorme fotografia que cobre uma parede inteira do estúdio Avedon: Charlie Chaplin retratado 
como um demônio, os dedos indicadores e mindinhos retos sobre a testa em forma de chifre ou garfo. "Fiz esta foto no último dia que passou nos Estados Unidos", explica Avedon, "poucas horas antes da partida do navio para a Europa. Veio aqui e..." Mas Pasolini se importa mais com a história de outras fotografias, como aquela do garoto negro que morreu devido aos ferimentos após ter sido agredido pela Ku Klux Klan. Ou deste mulato que foi eleito duas vezes para o Parlamento, mas nunca conseguiu entrar porque é contra a guerra no Vietnã. Ou este Allen Ginsberg que posa nu, coberto apenas pela sua barba e seus pelos, e o induz a mais uma declaração de amor: "Os intelectuais americanos, sabe, talvez sejam cheios de contradições. Encontra-se um aluno de Morris que escreveu sua tese sobre a poesia de Petrarca e discute sobre semiótica e depois se encontra duas estudantes que ignoram até mesmo Apollinaire ou Rimbaud. Elas perguntam quais são os seus poetas preferidos. Você responde Rimbaud, Appolinaire, Machado, Kavafis. Olham transtornadas. Que não conheçam Kavafis, tudo bem. Machado, já é grave, Apollinaire é um absurdo e Rimbaud chega a ser escandaloso. Mas, no entanto, possuem tanto respeito pela cultura! Um respeito cheio de receio, humildade, um grande dom. Agora veja os italianos: sempre donos do saber, mesmo quando ignorantes. Nos italianos nunca ocorre um momento de timidez em relação ao saber. Um tipo como Umberto Eco, por exemplo, conhece todo o saber e o vomita na cara dos outros com um ar indiferente. É como se você escutasse um robô. Um americano erudito como Umberto Eco é um homem humilde, nunca se considera dono da sua sabedoria, é quase assustado pela sua cultura. Gosto disso, acho isto justo...". No entanto, suponho que estas fotos feitas por Avedon são destinadas às fúteis leitoras da "Vogue". Que cena esta do Village.

Logo depois, Pasolini segue para o Village para comprar as calças e as jaquetas que acha tão elegantes e que em Roma não usará jamais, obcecado como é pelo complexo de ser reconhecido, criticado, observado. É atraído especialmente por uma camisa que é a cópia exata daquelas utilizadas nas prisões. Sobre o bolso esquerdo está escrito: "Presídio de Estado, detento Número 3678". Está experimentando, sentado, quando avista na esquina da 10th Avenue uma manifestação a favor da guerra no Vietnã. Homens e mulheres passam melancólicos com grandes cartazes onde está rabiscado: "Bombardeiem Hanói". Alguns possuem um distintivo que diz: "Matem todos aqueles vermelhos". Até que chega um automóvel, descem dois jovens e uma garota loira usando pantalonas. A garota carrega uma guitarra. Apoia-se no capô do carro, enquanto os dois jovens se colocam ao lado dela, e começa a tocar alguma coisa triste. Depois, juntos, os três atacam com uma música de protesto. Continuarão tocando enquanto os outros continuarão a desfilar com os seus cartazes, sem que ocorra uma briga, um insulto, um gesto de hostilidade. Pasolini permanece parado olhando-os, com a sua camisa de presidiário, seus olhos cheios d'água, afetuosos, quando sussurra:

"Esta foi a coisa mais linda que já vi na minha vida. É algo que não vou esquecer enquanto estiver vivo. Devo voltar, devo estar aqui mesmo se não tenho mais 
dezoito anos. Como me desagrada ter que partir, me sinto roubado. Me sinto como uma criança diante de um bolo, um bolo de várias camadas, e a criança não sabe qual camada vai gostar mais, sabe apenas que quer e deve comer todas. Uma por uma. E, no mesmo instante em que vai morder o bolo, o tiram dela". É a fotografia de um marxista em Nova York. 